\title{
MODOS
}

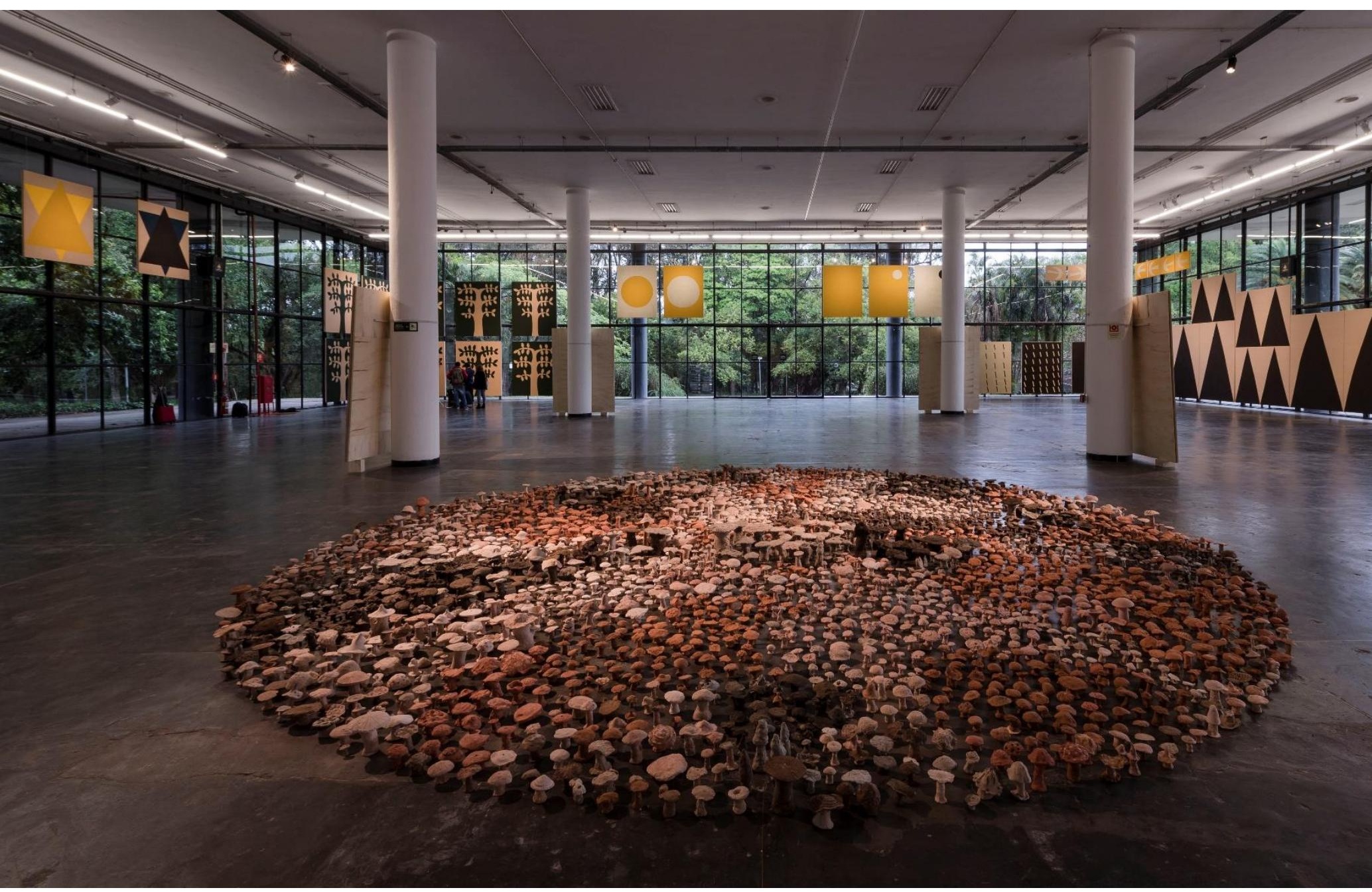

\section{Uma Bienal sem coesão interna}

\section{A Biennial without internal cohesion}

\author{
Ms. Maria Hirszman
}

Como citar:

HIRSZMAN, M. Uma Bienal sem coesão interna. MODOS. Revista de História da Arte. Campinas, v. 3, n.1, p.209-217, jan. 2019. Disponivel em: <https://www.publionline.iar.unicamp.br/index.php/mod/article/ view/4085>; DOI: https://doi.org/10.24978/mod.v3i1.4085.

Imagem:

Antonio Ballester Moreno, Vivan los campos libres, 2018. 33 Bienal de São Paulo. Fonte: Leo Eloy / Estúdio Garagem / Fundação Bienal de São Paulo. 


\title{
Uma Bienal sem coesão interna
}

\section{A Biennial without internal cohesion}

\section{Ms. Maria Hirszman *}

\begin{abstract}
Resumo
A $33^{\mathrm{a}}$ Bienal de São Paulo propôs uma diluição do papel da curadoria ao convidar 7 artistas-curadores para conceberem diferentes núcleos expositivos. Complementando essas mostras, o curador-geral Gabriel PérezBarreiro preparou 12 mostras individuais. Ao analisar o poder curatorial descentralizado em diferentes exposições e abordagens, sob o comando de um grupo heterogêneo de propostas, a resenha desenvolve 0 argumento de que esta edição da Bienal apresentou reduzido grau de articulação interna e falta de coesão entre as diferentes propostas apresentadas. A autora argumenta que a falta de uma maior tensão unificadora do conjunto acabou por levar a uma dispersão da relação direta entre o espectador e a obra de arte, exigindo um esforço maior por parte do público.
\end{abstract}

\section{Palavras-chave}

Bienal de São Paulo; curadoria; Gabriel Pérez-Barreiro; experiência estética; arte contemporânea.

\section{Abstract}

The 33rd São Paulo Biennial proposed a dilution of the curator's role by inviting 7 artists-curators to design different segments of the show. Complementing these segments, the general curator Gabriel Pérez-Barreiro prepared 12 individual exhibitions. In analyzing the decentralized curatorial power in these different expositions and approaches, under the command of a heterogeneous group of proposals, this review develops the argument that this edition of the Biennial presented a low level of internal articulation and a lack of cohesion among the different proposals presented. The author argues that the lack of a unifying tension of the ensemble ended up leading to a dispersion of the relationship between the spectator and the artwork, requiring a greater effort on the part of the public.

\section{Keywords}

São Paulo Biennial; curatorship; Gabriel Pérez-Barreiro; aesthetic experience; contemporary art. 
A Bienal de São Paulo procura reinventar-se a cada edição. Ao menos nas últimas décadas, a mostra tenta romper paradigmas do passado e criar novos caminhos, temáticos ou estruturais, para manter-se jovem, apesar de seus 67 anos de vida. Em 2018, o alvo da mudança foi ousado: o papel do curador foi desestruturado, e sua capacidade de articulação reduzida, em favor de uma estratégia descentralizada. Se isso permitiu uma exposição internamente mais diversificada e um espraiamento dos núcleos de poder, por outro lado parece ter havido um esgarçamento de seu poder reflexivo, uma diluição da capacidade da mostra de olhar com maior profundidade e agudeza para um conjunto articulado de questões.

A configuração da exposição ficou a cargo de um grupo de 7 artistas convidados, que propuseram projetos autônomos, em relação às suas próprias poéticas. A escolha dos nomes baseou-se claramente numa tentativa de criar um certo equilíbrio geográfico e de gênero, respeitando, de certa forma, uma partição igual entre homens e mulheres e seguindo uma divisão comum nas edições da Bienal de São Paulo de dedicar um terço da exposição a brasileiros, outro terço aos latino-americanos e um terceiro a representantes do restante do mundo. Cada um dos convidados atuou de forma isolada, em espaços e conceitos separados. Com ampla liberdade, tinham como única condição a presença obrigatória de seus trabalhos artísticos no núcleo a ser idealizado.

Até mesmo a museografia se distinguiu bastante, o que deu à mostra uma aparência heterogênea, formada por órgãos independentes que não estavam unidos por uma coluna vertebral comum. Tal diversidade é natural e até certo ponto interessante, enfatizando as múltiplas possibilidades de estruturação de uma interação entre diferentes poéticas. Ainda antes da abertura da mostra, o curadorgeral Gabriel Pérez-Barreiro, responsável por convidar os artistas-curadores, já havia manifestado seu desejo de que cada uma das exposições funcionasse como uma aula de curadoria. Mas a heterogeneidade também causou estranhamento.

O efeito provocado pelo labirinto barroco e pulsante organizado pela artista brasileira Sofia Borges, por exemplo, ganhou ainda mais impacto ao suceder o núcleo discreto, um tanto minimalista, de Antonio Ballester Moreno. No primeiro conjunto, do espanhol, parecia dominar a organização, o serialismo, a necessidade de compreender racional e esteticamente o mundo; enquanto que no segundo, da brasileira, mal se tinha tempo para pensar, e vivenciávamos de forma quase catártica o conjunto. 0 segmento concebido por Ballester Moreno, que teve o privilégio de receber os visitantes em seu primeiro contato com a exposição, tirou partido do espaço arejado. 0 esquema de distribuição das obras selecionadas fez com que estas respirassem em meio ao espaço amplo do pavilhão, dando uma sensação de despovoamento um tanto incomum para esta área do prédio, que, tradicionalmente, costuma ser abrigo para grandes intervenções por sua área ampla e pé direito elevado.

Até mesmo um dos trabalhos de maior impacto - seja em termos de dimensão, seja de presença frequente na mídia - acabou por parecer um tanto solitário em meio à vastidão em seu entorno. Tratase de uma instalação concebida pelo próprio Ballester Moreno, composta por centenas de cogumelos confeccionados em argila durante meses por crianças de escolas públicas e privadas de São Paulo. Outro trabalho de grande força nesse núcleo foi a ação Estação de campo: Parque Ibirapuera, de Mark Dion [fig.1]. $O$ artista se propôs a investigar, com a ajuda de uma equipe de talentosos aquarelistas, a 
natureza em torno do parque, retratando, à maneira de elegantes registros que relembram as notações botânicas do século XIX, uma diversidade de elementos coletados neste meio ambiente. De pássaros a tampinhas de caneta, os registros foram transformados em cartões de anotação, fundindo tempos históricos distintos e fazendo um comentário ao mesmo tempo irônico e crítico sobre a suposta "neutralidade" dos mapeamentos científicos.

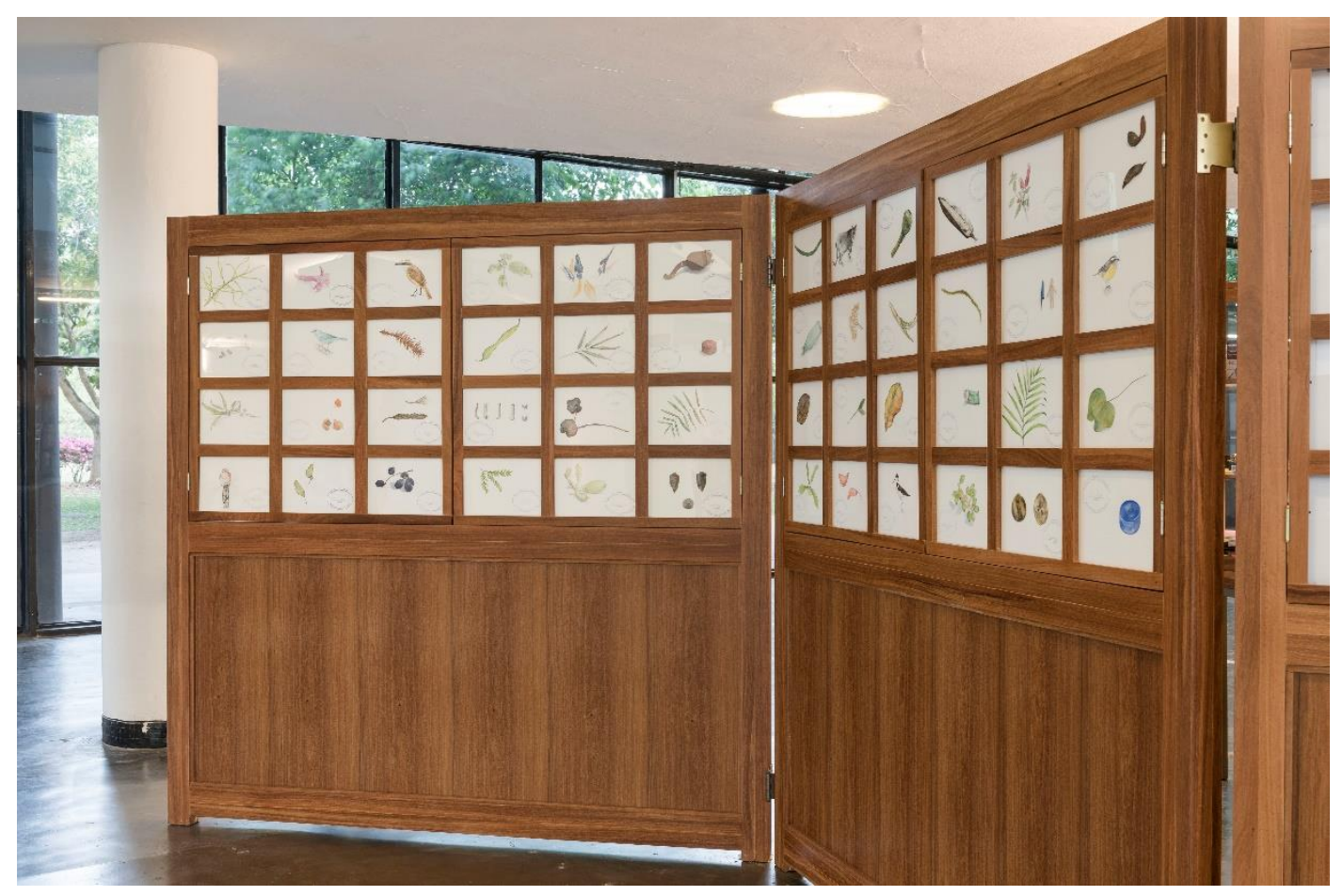

Fig. 1. Mark Dion, Field Station: Ibirapuera Park, 2018. 33ª Bienal de São Paulo. Fonte: Leo Eloy / Estúdio Garagem / Fundação Bienal de São Paulo.

Destacou-se ainda a sala dedicada a Friedrich Fröbel, pioneiro alemão do ensino infantil, responsável pela criação das bases do jardim da infância e de uma abordagem ao mesmo tempo lúdica e criativa do conhecimento. Foram trazidos à Bienal uma série de elementos e jogos por ele desenvolvidos para aplicação na formação das crianças, e que, de certa forma, estão intimamente ligados à estrutura formal e cromática da arte moderna. Não é mera coincidência que seus métodos de aprendizado tenham sido utilizados por mestres como Mondrian e Mies Van der Rohe.

0 entrecruzamento entre resgates históricos, entre diferentes campos de conhecimento (iluminando nexos da arte com a biologia e a pedagogia, por exemplo), e um interesse por representações plásticas que exploram e organizam a fronteira entre a abstração e a geometrização da realidade estavam na base da proposta elegante de Ballester Moreno.

Já no núcleo idealizado por Sofia Borges, os termos elegância, organização e método não se aplicaram. Ali ocorreu, pelo contrário, uma explosão de referências e encontros, que procuraram detonar no público 
reações imediatas e explosivas. Alguns pareceram se incomodar com o excesso de referências e a sobreposição de informações por vezes contrastantes. Mas é indiscutível que esse segmento da $33^{\mathrm{a}}$ Bienal foi a proposta mais disruptiva e ousada de todo o conjunto [fig.2]. Todas as peças estavam intimamente em conexão, criando uma conturbada rede de grande intensidade simbólica e formal, na qual se mesclaram uma ampla gama de elementos, como uma série de trabalhos do Museu de Imagens do Inconsciente, fotos e textos de parede da própria Sofia, esculturas e performances de Tunga ou um par de painéis em tecido dourado feitos por Leda Catunda (numa interessante reinvenção de sua produção). Tudo isso em uma elaborada cenografia, que explorou ângulos inusitados e abusou da sedutora textura de coloridas cortinas aveludadas.

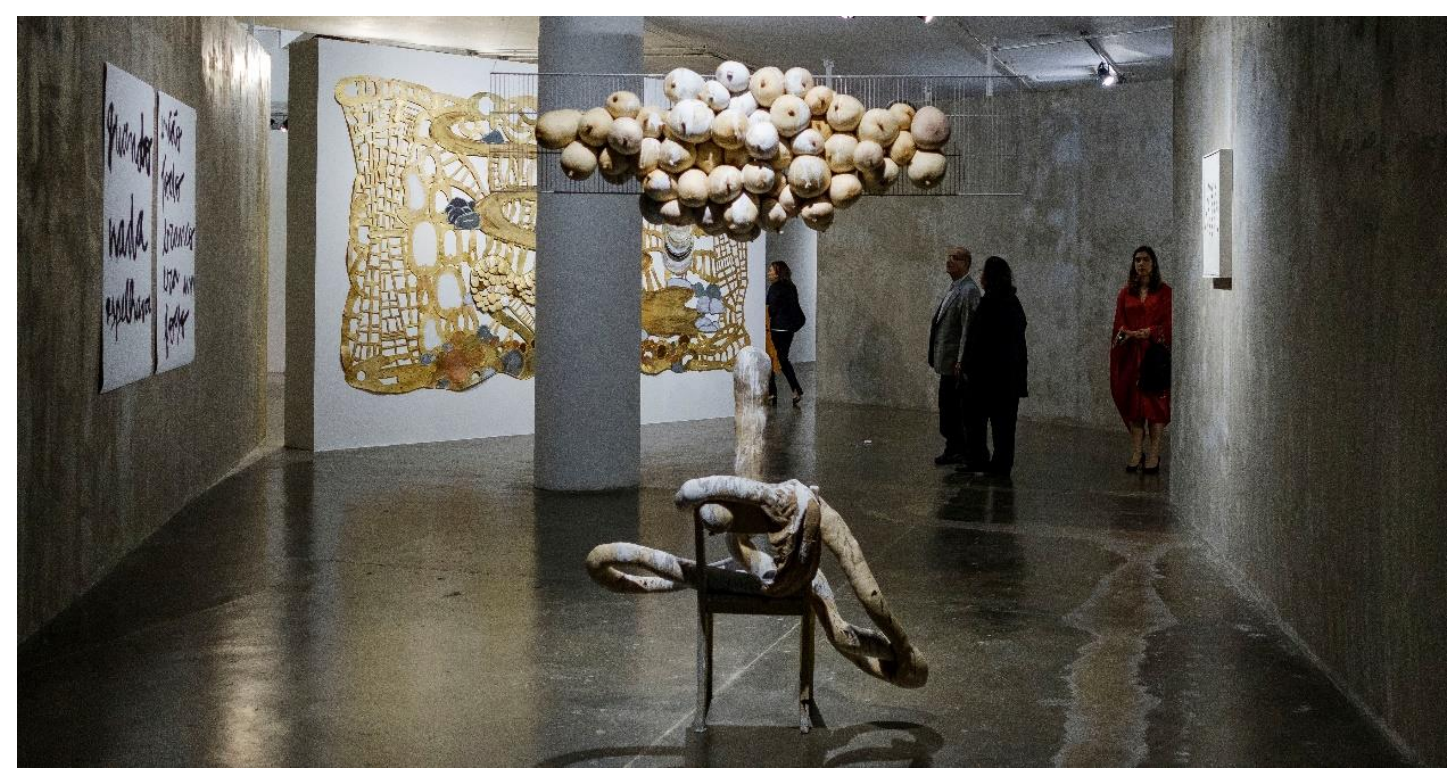

Fig. 2. Sofia Borges, Sem título, 2018; Leda Catunda, Eldorado, 2018; Sarah Lucas, Silver Hippie, 2016. $33^{a}$ Bienal de São Paulo. Fonte: Leo Eloy / Estúdio Garagem / Fundação Bienal de São Paulo.

$\mathrm{Na}$ defesa de seu projeto, Pérez-Barreiro sempre enfatizou a observação, a capacidade da arte nos aproximar do desconhecido sem precisar adotar um discurso. Mas a falta de uma maior tensão unificadora do conjunto acabou por levar a uma dispersão dessa relação direta entre o espectador e a obra de arte, exigindo que se recriasse a cada experiência um novo embate, a partir do zero, sem que uma experiência ajudasse a iluminar a seguinte. Foi o caso, por exemplo, dos núcleos coordenados pela argentina Claudia Fontes e por Wura-Natasha Ogunji, nascida nos Estados Unidos e baseada na Nigéria, responsáveis pela ocupação de boa parte do segundo andar do pavilhão. Mesmo trazendo trabalhos bastante potentes, como Nota de rodapé, da própria Claudia Fontes, e o vídeo Sala de visita, de Roderick Hietbrink, a não existência exatamente de uma conexão orgânica entre os diferentes elementos que os compuseram ia ficando cada vez mais evidente ao longo da visitação. Os trabalhos das duas artistas-curadoras de certa forma servem como metáforas dessa fluidez e desconexão de sentidos. 
Nota de rodapé apresentou ao público, sobre uma longa mesa revestida de tecido azul, centenas de fragmentos envelopados em tecido branco e identificados por palavras supostamente aleatórias [fig.3], quando na verdade foram extraídas de uma narrativa criada a pedido de Claudia para nortear sua apresentação na Bienal, intitulada $O$ pássaro lento. Quanto aos fragmentos, eram cacos de pássaros de porcelana destruídos por pássaros de verdade e posteriormente embalados, como patuás de um processo autorreferente de construção poética. Tanto os destroços como as palavras são vestígios, afetivos e simbólicos, de uma realidade que não existe mais. Já Wura-Natasha Ogunji pontuou seu espaço - surpreendentemente amplo e vazio - com uma fascinante cortina de fitas de diferentes cores. As cordas pendiam soltas de um varal, sem ter entre si nenhuma conexão de função ou sentido além de habitarem um mesmo lugar no mundo. Não amarravam nada, nem propunham nenhuma ação coletiva.

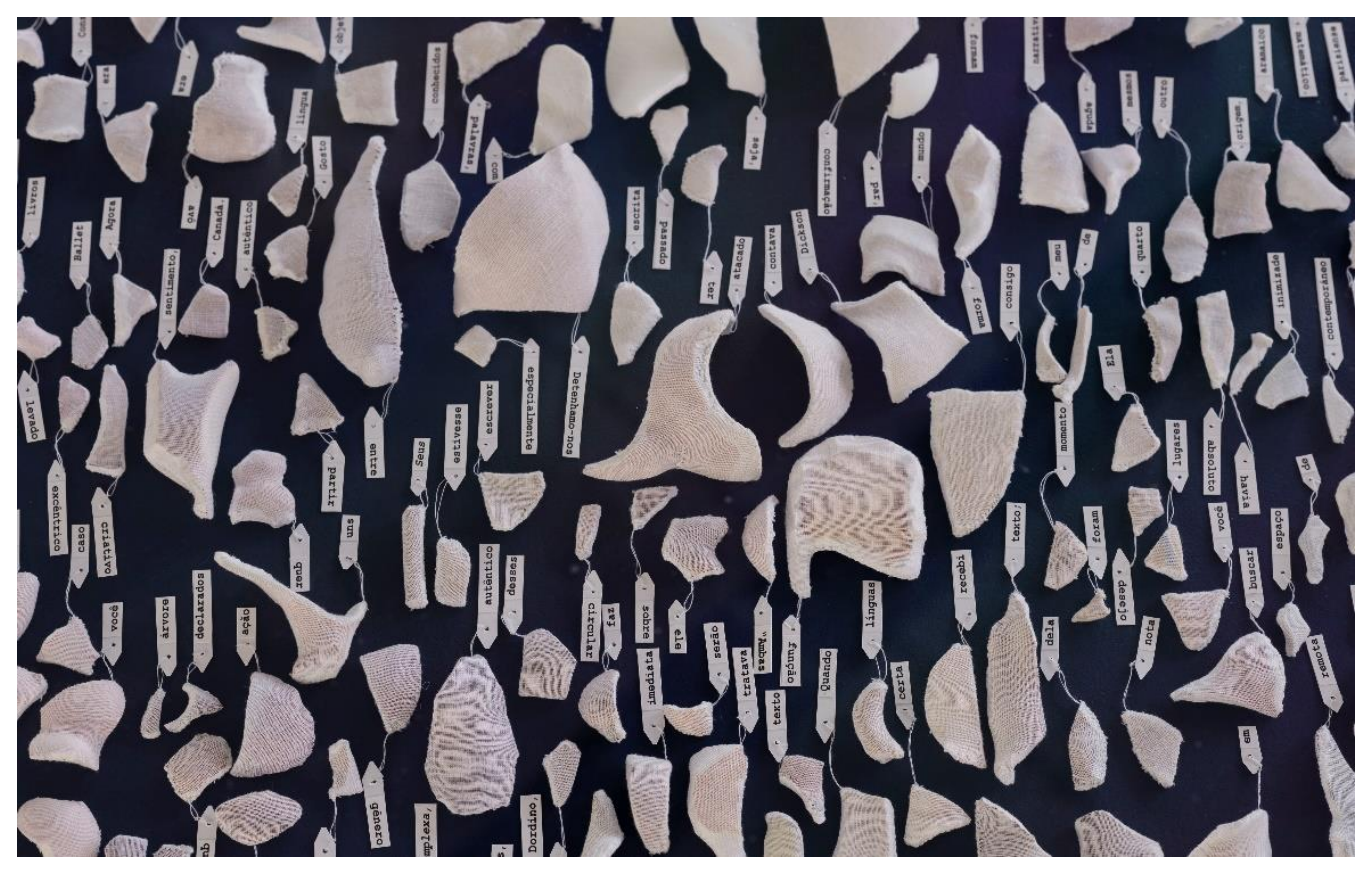

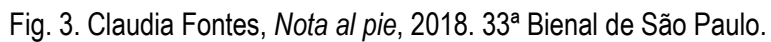
Fonte: Leo Eloy / Estúdio Garagem / Fundação Bienal de São Paulo.

Esse esgarçamento de sentidos foi menos intenso no segmento proposto pelo argentino Alejandro Cesarco - que apresentou um conjunto coeso de trabalhos que se debruçam sobre questões como a representação e os processos de traduções, repetições e reescrituras de sentido na arte (com uma presença densa de pesquisas conceituais) -, desaparecendo ainda mais nos núcleos que ficaram sob a responsabilidade de Mamma Anderson e Waltercio Caldas - que, mesmo mantendo-se isolados do resto da mostra, conseguiram um alto grau de coesão interna entre os trabalhos que selecionaram para dialogar com suas próprias produções. E mantiveram esses nexos entre as diferentes obras, fazendo com que uma experiência estética de certa forma ecoasse e modificasse a seguinte. 
Seguindo e tornando mais complexo 0 modelo já experimentado na $6^{a}$ Bienal do Mercosul, cuja curadoria-geral também ficou a cargo de Pérez-Barreiro, Waltercio propôs uma seleção mais de obras do que de autores [fig.4]. O princípio norteador de suas escolhas foi de caráter bastante subjetivo e, segundo ele, reflexo da importância que os trabalhos escolhidos têm ou tiveram em sua própria produção. Evidentemente, não se trata de um núcleo coeso, mas sim de um conjunto de obras em diálogo que tangenciam questões - formais, temáticas ou poéticas - que de certa forma ecoam na produção do próprio Waltercio. É a partir da obra do artista-curador que se justifica o encontro entre autores tão diferentes como Victor Hugo (o escritor, que também teve seus momentos de aquarelista), Antonio Dias ou Gego. Pode-se dizer que nesse encontro as conversas se deram em pequenos grupos, organizados em função de afinidades diversas e misteriosas, que ora sublinhavam cores e formas, ora formas de raciocínio plástico semelhantes. É interessante notar, por exemplo, como o olhar afetivo de Waltercio encontra nexos ocultos. Mas essa força, evidente em alguns ângulos ou segmentos do núcleo, foi prejudicada pela montagem. A opção por não legendar individualmente as obras - possivelmente para não contaminar a apreensão da obra específica com o nome de seu autor - acabou tornando a visita ao segmento um verdadeiro quebra-cabeças, obrigando o visitante a fazer várias idas e vindas para descobrir autorias e títulos, num esforço que só faz reduzir a conexão direta com a obra em questão.

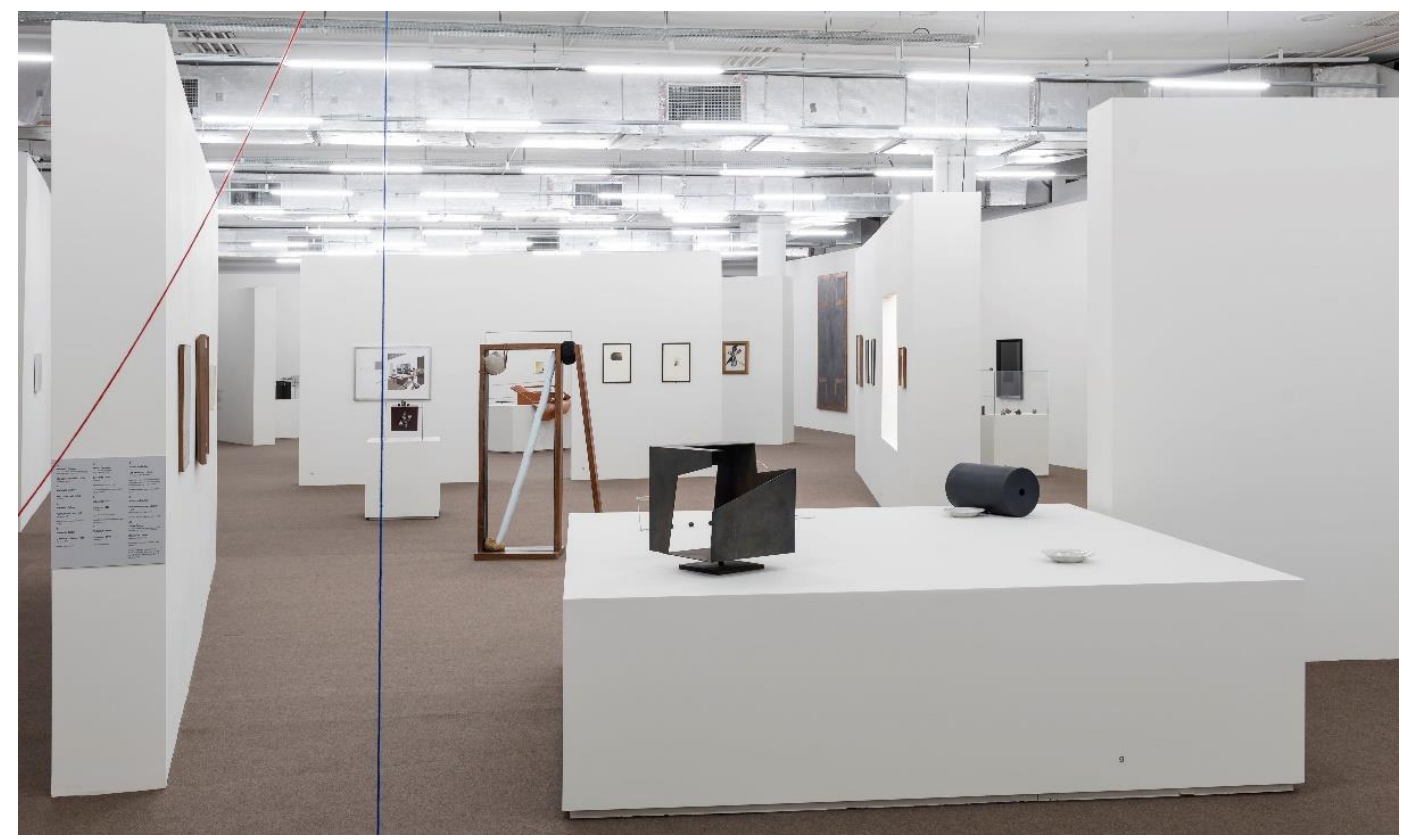

Fig. 4. Waltercio Caldas, O ar mais próximo, 1991; Tunga, Sem título, 2015; Jorge Oteiza, Caja vacía, 1958; Waltercio Caldas, Tubo de ferro / Copo de leite; Prato comum com elástico, 1978. 33ª Bienal de São Paulo. Fonte: Leo Eloy / Estúdio Garagem / Fundação Bienal de SP.

Tal aspecto não ocorreu com a seleção de Mamma Anderson [fig.5]. Ao contrário de Waltercio, que contemplou um grande número de artistas e um leque maior ainda de obras, a pintora sueca centrou sua atenção sobre uma reunião bem mais reduzida de criadores. Além dela própria, presente com uma 
seleção de potentes pinturas em que a solidão e o recolhimento parecem dominar, Mamma selecionou uma dúzia de autores pouco conhecidos no Brasil. Muitos deles são de origem nórdica, vários tiveram problemas pessoais de saúde, física e mental, tendo encontrado na elaboração de construções plásticas e poéticas uma forma de se relacionar com o mundo, elaborando visualmente angústias, ansiedades e criando poéticas com uma forte dose de melancolia, acidez e crítica. Destaques como 0 filme de Ladislas Starewitch, uma surreal aventura detetivesca na forma de uma animação cujos protagonistas são insetos, ecoa nas estranhas histórias desenhadas pelo norte-americano Henry Darger narrando o processo de libertação de crianças escravizadas. 0 resultado foi um ambiente de forte tensão, amplificado pelo trabalho sonoro de Åke Hodell, uma ácida gravação de vozes de crianças falando sobre um certo Mr. Smith, que foi o último presidente branco da Rodésia. Os comentários sobre ele seguem uma escala crescente e angustiante, indo da versão "oficial" do bondoso homem branco à declaração de que, na verdade, ele é um assassino. A virulência anti-imperialista deste trabalho é tão intensa que chegou a ter sua execução proibida na rádio sueca entre os anos de 1969 e 1985 devido à pressão do governo colonial britânico.

Curiosamente, tanto este núcleo idealizado por Mamma Anderson como aquele projetado por Waltercio Caldas (que ocuparam o terceiro andar do pavilhão) ficaram pontuados por potentes resgates históricos e mesclaram de forma ao mesmo tempo despretensiosa e reveladora produções contemporâneas a obras resgatadas de um passado distante, como ícones russos do século XVI ou XVII, ou um time potente de artistas modernos, atuantes na primeira metade do século XX. Tal resgate privilegiou uma visão mais longa da história do que a praticada nas últimas edições da Bienal, permitindo inserir a apreciação da produção atual num contexto histórico mais rico.

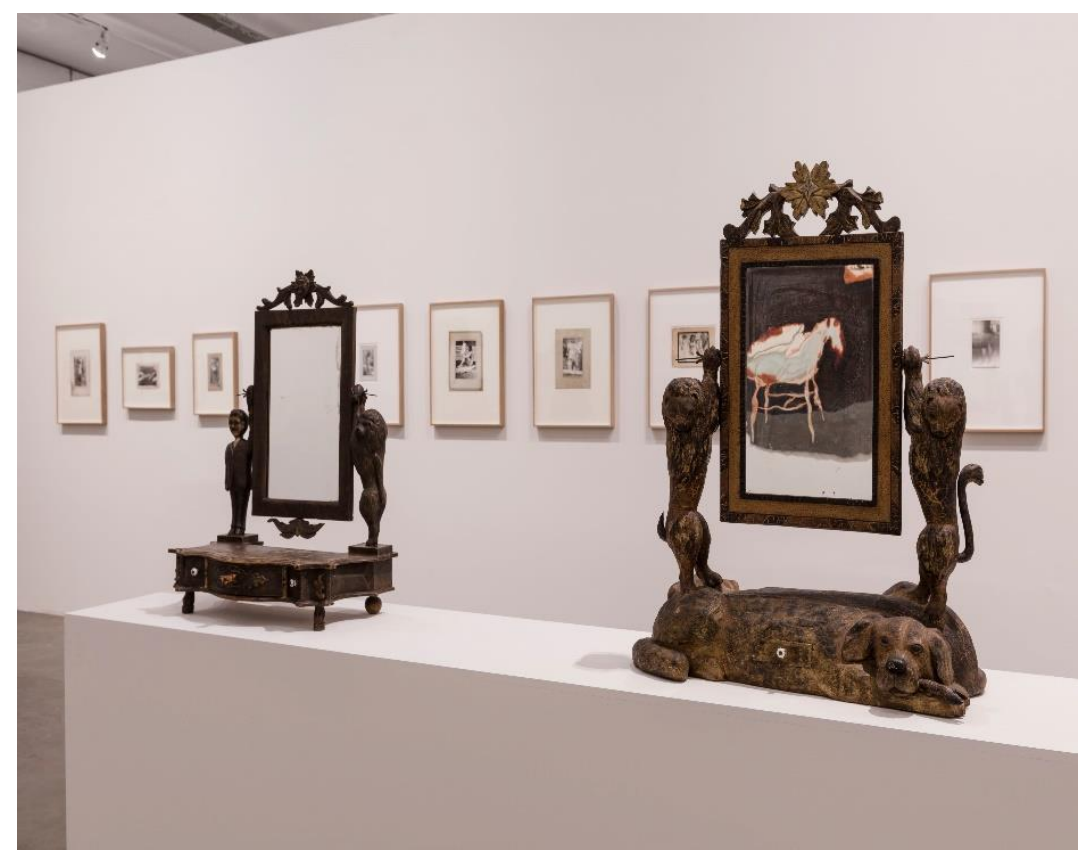

Fig. 5. Vista da exposição de Mamma Anderson: Lim-Johan, Sem título [Untitled], s.d. [n.d.]. 33ª Bienal de São Paulo. Fonte: Leo Eloy / Estúdio Garagem / Fundação Bienal de SP. 
Se nos núcleos organizados pelos artistas curadores já predominava a sensação de alheamento e falta de coesão com o resto da exposição, tal fenômeno ganhou ainda mais evidência quando analisamos os 12 artistas escolhidos pelo próprio Pérez-Barreiro para as mostras individuais. Os critérios de seleção adotados foram demasiadamente frouxos e acabaram por gerar exposições encapsuladas sobre si mesmas, muito diferentes entre si e espalhadas ao longo do pavilhão sem critérios expositivos claros. O que deu por vezes a impressão de servirem apenas para completar os amplos espaços do prédio.

A principal exceção foi a mostra dedicada a Aníbal López (1964-2014), que trouxe um conjunto amplo e potente de obras do artista guatemalteco. Tratou-se de um dos raros exemplos de obras politicamente mais assertivas nesta Bienal, que, explicitamente, optou por investigar questões de cunho mais formal, construtivo ou processual. A obra de Lopes, que assinava seus trabalhos usando o número de sua carteira de identidade (A-1 53167), lida com questões nevrálgicas como a violência. Destacou-se também o conjunto de trabalhos de Lucia Nogueira (1950-1998), artista brasileira consagrada na Europa e que até então era praticamente desconhecida em nosso país. Lidando com materiais banais do cotidiano, como ventiladores, sacos plásticos e móveis singelos, o trabalho de Lucia cria momentos de estranhamento e desconforto que perturbam o espectador.

A dispersão excessiva e o caráter um tanto morno desses projetos individuais (como foram chamadas as mostras individuais de artistas escolhidos pelo próprio Pérez-Barreiro) só fizeram confirmar o diagnóstico geral de que a $33^{\mathrm{a}}$ Bienal cumpriu seu papel de apresentar ao público distintas formas de sentir e pensar sobre arte, mas de modo cacofônico, sem aproveitar ao máximo a capacidade que um trabalho tem de transformar o outro. Qualquer tentativa de amarrar os vários laços que compuseram esta gigantesca mostra se revelaria infrutifera. Se, por um lado, a inexistência de um modelo dominador pode ser celebrada, abrindo espaço para diferentes formas de expressão num mesmo evento que se quer panorâmico; por outro lado, ficou uma sensação de desamparo, de impossibilidade de síntese, que desse conta do conjunto e um anseio por um nível de troca mais profundo e intenso.

\section{Nota}

\footnotetext{
* Jornalista, curadora e crítica de artes. Atua na área de artes visuais desde 1996, colaborando para diversas publicações, como 0 Jornal da Tarde, o Estado de S. Paulo, Revista Pesquisa Fapesp e Arte!Brasileiros. É pesquisadora em história da arte, com mestrado pela Escola de Comunicações e Artes da Universidade de São Paulo (ECA-USP), além de integrar o Grupo de Estudos Arte\&Fotografia da ECA-USP e o Conselho Editorial da Enciclopédia de Artes Visuais do Itaú Cultural. E-mail: mariahirs@gmail.com.
}

Texto recebido em novembro de 2018. Aprovado em dezembro de 2018. 